\title{
Progressive Loss of Dopaminergic Neurons in the Ventral Midbrain of Adult Mice Heterozygote for Engrailed1
}

\author{
Laure Sonnier, ${ }^{1 \star}$ Gwenaëlle Le Pen, ${ }^{2 *}$ Andreas Hartmann, ${ }^{3}$ Jean-Charles Bizot, ${ }^{4}$ Fabrice Trovero, ${ }^{4}$ Marie-Odile Krebs, ${ }^{2}$ \\ and Alain Prochiantz ${ }^{1}$ \\ ${ }^{1}$ Centre National de la Recherche Scientifique, Unité Mixte de Recherche 8542, Development and Evolution of the Nervous System, Group Development and \\ Neuropharmacology, Ecole Normale Supérieure, 75230 Paris Cedex 05, France, ${ }^{2}$ Institut National de la Santé et de la Recherche Médicale, Unit 796, \\ Pathophysiology of Psychiatric Disorders, University Paris Descartes, Faculty of Medicine Paris Descartes, Sainte-Anne Hospital, Paris F-75014, France, \\ ${ }^{3}$ Institut National de la Santé et de la Recherche Médicale, Unit 679, Neurology and Experimental Therapeutics, Hospital of Pitié-Salpêtrière and University \\ Pierre and Marie Curie, Faculty of Medicine, Paris 75013, France, and ${ }^{4}$ Keyobs, Centre d'Innovation, 45100 Orléans Cedex 2, France
}

Engrailed1 and Engrailed2 (En1 and En2) are two developmental genes of the homeogene family expressed in the developing midbrain. $E n 1$ and, to a lesser degree, $E n 2$ also are expressed in the adult substantia nigra (SN) and ventral tegmental area (VTA), two dopaminergic (DA) nuclei of the ventral midbrain. In an effort to study En1/2 adult functions, we have analyzed the phenotype of mice lacking one En1 allele in an En2 wild-type context. We show that in this mutant the number of DA neurons decreases slowly between 8 and 24 weeks after birth to reach a stable 38 and 23\% reduction in the SN and VTA, respectively, and that neuronal loss can be antagonized by En2 recombinant protein infusions in the midbrain. These loss and gain of function experiments firmly establish that $E n 1 / 2$ is a true survival factor for DA neurons in vivo. Neuronal death in the mutant is paralleled by a $37 \%$ decrease in striatal DA, with no change in serotonin content. Using established protocols, we show that, compared with their wild-type littermates, En $1+/-$ mice have impaired motor skills, an anhedonic-like behavior, and an enhanced resignation phenotype; they perform poorly in social interactions. However, these mice do not differ from their wild-type littermates in anxiety-measuring tests. Together, these results demonstrate that En1/2 genes have important adult physiological functions. They also suggest that mice lacking only one $E n 1$ allele could provide a novel model for the study of diseases associated with progressive DA cell death.

Key words: Engrailed; dopamine; behavior; cell death; Parkinson; mouse

\section{Introduction}

Homeoproteins, a class of transcription factors encoded by homeogenes, have been studied primarily during development but also are expressed at late developmental stages and in the adult. Some adult functions probably are related to the persistence of plastic events in the mature nervous system (Morgan, 2006), for example the differentiation of adult stem cells or the morphological changes accompanying physiological activity. However, another possibility is that the adult expression of homeogenes serves new functions unrelated to development.

During development the mesencephalic dopaminergic (DA)

\footnotetext{
Received 0ct. 23, 2006; revised Dec. 20, 2006; accepted Dec. 20, 2006.

This work was supported by Centre National de la Recherche Scientifique (CNRS), Institut National de la Recherche Médicale, and Ecole Normale Supérieure. Specific support also was obtained from the Association Française contre les Myopathies (Grant 2006-12208), Fondation de France (Grant 2004-013352), and Michael J. Fox Foundation (Fast Track 2004 Award). We thank Dr. Marie-Françoise Chesselet for her careful reading of this manuscript and valuable advice. Our thanks also go to Dr. Armen Sagatelyan and Professor Michel Volovitch for their help in designing and analyzing some experiments. We are grateful to Stéphane Dupas (CNRS; UMR8542), Sabrina David, Alexandra Herpin, and Stéphanie Pothion (Keyobs) for excellent technical assistance.

* L.S. and G.L.P. have contributed equally to this work.

Correspondence should be addressed to Alain Prochiantz, Centre National de la Recherche Scientifique, Unité Mixte de Recherche 8542, Development and Evolution of the Nervous System, Group Development and Neuropharmacology, Ecole Normale Supérieure, 46 Rue d'Ulm, 75230 Paris Cedex 05, France. E-mail: Alain.Prochiantz@ens.fr. D0I:10.1523/JNEUROSCI.4583-06.2007

Copyright $\odot 2007$ Society for Neuroscience $\quad$ 0270-6474/07/271063-09\$15.00/0
}

neurons of the substantia nigra (SN) and the ventral tegmental area (VTA) are determined by the sequential expression of growth and transcription factors. LIM homeobox transcription factor $1 \beta$ (Lmxb1) and nuclear receptor-related subfamily 1 (Nurr1) transcription factor act very early in the chain of events leading to DA cell determination (Prakash and Wurst, 2006). In contrast, pentraxin-related gene 3 (Ptx3) and Engrailed1 (En1) homeogenes intervene at later stages of DA cell development. Indeed, Ptx3 plays a role in the early morphological differentiation of DA neurons (Smidt et al., 2004b), and En1, possibly also Engrailed2 (En2), is part of the survival DA toolbox (Simon et al., 2001; Sgado et al., 2006).

During development $E n 1$ is expressed first at the one-somite stage, and its invalidation results in nearly complete midbrain absence (Wurst et al., 1994). En2 expression is detected at the five-somite stage, and its deletion gives rise primarily to a cerebellar phenotype (Joyner et al., 1991; Gerlai et al., 1996). Knocking En2 into En1 allows for midbrain development and mouse survival, suggesting that the two proteins are equivalent in the midbrain, at least at this level of analysis (Hanks et al., 1995).

In the adult En2 is expressed in the tectum, SN, and VTA, but its strongest site of expression is the granule cell layer in the cerebellum. In contrast, En1 expression is predominant in the tectum, $\mathrm{SN}$, and VTA. In the two latter structures $E n 1$ and $E n 2$ are 
expressed in the DA cells (Simon et al., 2001). One likely function of En1/2 is DA cell survival. Indeed, the deletion of the two En1 and one/two En2 alleles leads to the prenatal loss of DA neurons in the VTA and SN, and the extent of DA loss, probably via apoptosis (Alberi et al., 2004), reflects the number of $E n 1 / 2$ alleles deleted (Simon et al., 2001). Furthermore, the deletion of one $E n 1$ and two En2 alleles (three En alleles of four) leads to massive DA cell death in the SN of young adult mice, but not in the VTA (Sgado et al., 2006).

In the present work we have used a mutant mouse line in which only one En1 allele has been deleted in an En2 wild-type context that preserves cerebellar integrity. We show that, in this "mild Engrailed mutant" lacking one allele of four, the number of DA neurons is reduced specifically and progressively with age from 8 to 24 weeks postnatal and then remains stable. DA loss affects both the SN and VTA, gives rise to a strong hypo-DA phenotype, and can be antagonized by the local infusion of En2 protein.

\section{Materials and Methods}

Animals. Wild-type (WT) female Swiss mice (Janvier, Le Genest-St.-Isle, France) were crossed with En $1 \mathrm{LacZ}+/-, E n 2+/+$ (referred to in this work as En1+/-) male mice (in which lacZ is inserted in the $E n 1$ locus by homologous recombination (Hanks et al., 1995) maintained on a WT Swiss background for $>10$ generations. Heterozygous mutant mice were identified by PCR with the use of LacZ primers. Male WT and En1+/littermates were housed in groups of 6-10 per cage $(45 \mathrm{~cm}$ deep, $30 \mathrm{~cm}$ wide, $20 \mathrm{~cm}$ high), except for the saccharin consumption test in which mice were housed individually, kept on a $12 \mathrm{~h}$ light/dark cycle (lights on, 7 A.M.) and had free access to food (food for rats and mice A04, Scientific Animal Food and Engineering, Epinay-sur-Orge, France) and water. The ambient temperature of the room was maintained at $21.5 \pm 1.5^{\circ} \mathrm{C}$. For immunohistochemistry and stereological count of DA cells in SN and VTA five different batches of mice were used corresponding to $3,8,16$, 24 , and $48 \mathrm{~d}$ postnatal. Groups of $n=3-4$ mice per genotype were analyzed. Those animals were not tested previously for behavior. For striatal monoamine level evaluation one batch of mice at 55 weeks postnatal was used ( $n=8$ for WT; $n=10$ for $E n 1+/-$ ). These animals were not tested previously for behavior. For behavioral studies three batches of mice were used. Batch 1 (WT, $n=19 ; E n 1+/-, n=19$ ) was subjected to the open-field test at the age of 24 weeks. Batch 2 (WT, $n=9 ; E n 1+/-$, $n=10$ ) was subjected to elevated plus maze and locomotor activity tests at the age of 24 weeks, social interaction test at the age of 25 weeks, the forced swimming test at the age of 26 weeks, rotarod at 27 weeks, and the saccharin consumption test at the age of 35 weeks. Batch 3 was subjected to amphetamine administration and horizontal locomotor activity evaluation at 32-33 weeks postnatal (WT, $n=12 ; E n 1+/-, n=12$ ).

Immunohistochemistry. Animals were anesthetized with pentobarbital $(130 \mathrm{mg} / \mathrm{kg}$; Sigma, St. Quentin, France) and perfused transcardially with $4 \%$ paraformaldehyde (PFA) in $0.1 \mathrm{M}$ phosphate buffer (PB). Brains were removed, postfixed, and cryoprotected. Immunohistochemistry was performed as described previously (Hirsch et al., 1988) on free-floating cryomicrotome-cut sections ( $20 \mu \mathrm{m}$ in thickness) encompassing the entire midbrain. After incubation in $3 \% \mathrm{H}_{2} \mathrm{O}_{2} / 20 \%$ methanol, followed by $0.2 \%$ Triton X-100 and by $4 \%$ bovine serum albumin in $0.1 \mathrm{PBS}$, the sections were incubated overnight at $4^{\circ} \mathrm{C}$ with a polyclonal antibody against tyrosine hydroxylase (TH) (1:1000; Pel-Freez Biologicals, Rogers, AR). Sections then were treated with secondary antibodies (Vectastain, Vector Laboratories, Burlingame, CA) and subsequently were incubated with avidin-biotinylated horseradish peroxidase complex. Peroxidase was revealed by incubation with $0.05 \% 3,3^{\prime}$-diaminobenzidine tetrahydrochloride containing $0.008 \%$ hydrogen peroxide. Sections were analyzed on a Nikon Optiphot 2 microscope with ExploraNova VisioScan T4.18 software (La Rochelle, France) as previously described (Hoglinger et al., 2003). Cell counts were quantified stereologically on regularly spaced sections covering the whole rostrocaudal extent of the $\mathrm{SN}$ with the
VisioScan stereology tool. The SN was identified according to established anatomical landmarks (Paxinos mouse brain atlas).

For fluorescent immunohistochemistry the free-floating cryomicrotomecut sections (20 $\mu \mathrm{m}$ in thickness) were incubated for $1 \mathrm{~h}$ in PBS, $0.2 \%$ Triton X-100, and $10 \%$ fetal calf serum (FCS). Primary antibodies against TH (1:1000; Pel-Freez Biologicals) and neuronal marker NeuN (1:1000; Chemicon, Temecula, CA) were added overnight at $4^{\circ} \mathrm{C}$ before the addition of anti-mouse FITC (1:1000; Jackson ImmunoResearch, West Grove, PA) and anti-rabbit cyanine 3 (1:2000; Jackson ImmunoResearch) antibodies. Sections were analyzed by confocal microscopy. $\mathrm{TH}$ staining was used to delimit the $\mathrm{SN}$, and NeuN-positive cells were counted in the delimited area by using NIH ImageJ software (Bethesda, $\mathrm{MD})$.

Statistical differences were assessed by two-way ANOVAs (genotype status $\times$ cell counts), followed by post hoc Tukey honest significant differences (Tukey HSD) tests when appropriate $(n=3-4$ mice by group of age and genotype).

Engrailed recombinant protein infusion. En2 recombinant protein was produced in bacteria as described previously (Foucher et al., 2003) and dialyzed overnight at $4^{\circ} \mathrm{C}$ against $0.09 \% \mathrm{NaCl}$ before infusion. Mice were infused for $14 \mathrm{~d}$ above the $\mathrm{SN}$ (anterior, 0.27 ; lateral, $0.8 ; \Delta, 2.75$ relative to $\lambda$ ) with micro-osmotic pumps $(0.3 \mu \mathrm{l} / \mathrm{h}$; model 102 ALZET, Durect, Cupertino, CA). Six WT mice and three En $1+/-$ mice were infused with saline $(0.09 \% \mathrm{NaCl})$, and three WT mice and three $E n 1+/-$ mice were infused with En2 recombinant protein $(150 \mu \mathrm{g} / \mathrm{ml}$ En 2 and $10 \mu \mathrm{g} / \mu \mathrm{l}$ colominic acid in $0.09 \% \mathrm{NaCl}$ ) between postnatal weeks 6 and 8 . Animals were killed at 9 weeks by a $4 \%$ PFA infusion; their brains were removed, postfixed for $24 \mathrm{~h}$ at $4^{\circ} \mathrm{C}$ in $4 \%$ PFA, cryoprotected with $10 \%$ sucrose, frozen in isopentane at $-30^{\circ} \mathrm{C}$, and stored at $-80^{\circ} \mathrm{C}$.

Sections were immunostained for Engrailed to analyze the location of the exogenous En2 protein. Free-floating cryomicrotome-cut sections (20 $\mu \mathrm{m}$ in thickness) encompassing the entire midbrain were heated in $1 \times \mathrm{PBS}$ overnight at $65^{\circ} \mathrm{C}$ to inhibit endogenous alkaline phosphatase (AP) activity, blocked for $30 \mathrm{~min}$ at room temperature (RT) in $1 \times \mathrm{PBS}$, $300 \mathrm{~mm} \mathrm{NaCl}, 1 \%$ Triton X-100, and 10\% FCS, and incubated overnight at $4^{\circ} \mathrm{C}$ with an anti-Engrailed rabbit polyclonal antibody $(86.8$, produced in the laboratory; $1: 2000)$. Sections then were treated with anti-rabbit biotin-IgGs (1:2000) for $2 \mathrm{~h}$ at RT and AP-streptavidin (1:2000) for 30 min at RT. AP activity was revealed by using nitroblue tetrazolium/5bromo-4-chloro-3-indolyl phosphate (NBT/BCIP) overnight at RT and stopped with PBS. Sections were post-fixed for $30 \mathrm{~min}$ in $4 \%$ PFA.

Stereological counts of TH-positive cells in the $\mathrm{SN}$ were done by using the stereological protocol described above. Statistical differences were assessed by two-way ANOVA, followed by Fisher least significant differences (LSD) post hoc test.

Striatal monoamine levels. Animals were decapitated at 55 weeks, and total striae were dissected and stored at $-30^{\circ} \mathrm{C}$ until use. Tissues were homogenized (Potter Teflon) in $500 \mu \mathrm{l}$ of $0.1 \mathrm{~N}$ perchloric acid (for catecholamines) or chlorhydric acid (for indolamines) containing $0.05 \%$ of sodium metabisulfites. After centrifugation $(25,000 \times g$ for $30 \mathrm{~min}$ at $4^{\circ} \mathrm{C}$ ) the supernatants were injected into a liquid chromatograph coupled to a mass spectrometer (Finnigan LCQ, Thermo Fisher Scientific, Waltham, MA). Compounds were separated on a C18 column operating in inverse phases. The eluted amines were monitored by using electrospray ionization tandem mass detection in positive ion mode. Differences in striatal monoamine levels were compared by using the Student's $t$ test ( $n=8$ for WT; $n=10$ for En1+/-).

Open field. Activity was measured in a $15 \mathrm{~min}$ session in four Plexiglas transparent open fields ( $44.5 \mathrm{~cm}$ long, $44.5 \mathrm{~cm}$ wide, $40 \mathrm{~cm}$ high). The distance traveled (in centimeters), the number of rearings, and the time spent in the central zone of the open field $\left(22.5 \times 22.5 \mathrm{~cm}^{2}\right)$ were recorded in 5 min periods with infrared photobeam detection systems (ActiTrack, LSI LETICA, Panlab, Barcelona, Spain). Two-way ANOVAs (genotype status $X$ time period) with repeated measures on time period were used to test for significant differences between WT and En1+/mice.

Amphetamine treatments. The effect of administrations of amphetamine (sulfate salt; Sigma) on open-field motor activity was studied in one $60 \mathrm{~min}$ session at a dose of $5 \mathrm{mg} / \mathrm{kg}$ and in three $60 \mathrm{~min}$ sessions at 
$48 \mathrm{~h}$ intervals at a dose of $2 \mathrm{mg} / \mathrm{kg}$. Animals in each group were divided randomly in two subgroups and received either saline or amphetamine intraperitoneally $30 \mathrm{~min}$ after being placed in the open field. The distance traveled (in centimeters) was recorded during $30 \mathrm{~min}$ periods before (data not shown) and $30 \mathrm{~min}$ after the injection. Two-way ANOVA for repeated measures was used to determine the influence of treatment, genotype, and session number, followed by post hoc comparison with the Student's $t$ test when appropriate.

Accelerating rotarod. Balance and motor coordination were tested by using a constant-speed rotarod treadmill (Model 7600 with a $3 \mathrm{~cm}$ in diameter rod; Ugo Basile, Comerio, Italy). The time spent by the mouse on the rotarod was recorded up to a maximum of $120 \mathrm{~s}$, with speeds varying from 16 to $32 \mathrm{rpm}$ at $4 \mathrm{rpm}$ incremental steps. Each animal was trained over $3 \mathrm{~d}$ (three trials per speed with an interval of at least $4 \mathrm{~h}$ between blocks). Two-way ANOVAs (genotype status $\times$ rotation speed) with repeated measures on rotation speed were used to test for significant differences between WT and En1+/- mice.

Forced swimming test. Depression-related behaviors were evaluated by using the forced swimming test (FST) (Porsolt et al., 1977). This test has been performed as described by Ventura and colleagues (2002) with minor modifications. Mice were placed individually into glass cylinders (height, $25 \mathrm{~cm}$; diameter, $55 \mathrm{~cm}$ ) containing $20 \mathrm{~cm}$ of water at $25-26^{\circ} \mathrm{C}$ during two sessions $24 \mathrm{~h}$ apart. The first session lasted $10 \mathrm{~min}$ and the second for $6 \mathrm{~min}$. The two sessions were videotaped; later on, an observer unaware of animal status measured immobility time. A mouse was judged to be immobile when it floated in an upright position and made only small movements to keep its head above water.

Two-way ANOVAs (genotype status $\times$ time period) with repeated measures on time period were used to test for significant differences between WT and En1+/- mice in FST. When significant differences were found in immobility time and motor activity, analyses of covariance (ANCOVAs) were conducted to determine phenotype independence. To that end, animals tested in FST were evaluated previously in the open field to assess their locomotor activity. The horizontal locomotor activity (in centimeters) of the animals was measured by video tracking (SMART, Bioseb, Chaville, France) for a $10 \mathrm{~min}$ period. The individual compartments $(40 \times 40 \times 30 \mathrm{~cm})$ were in a dimly lit quiet room. The obtained locomotor activity data were analyzed by a separate two-way ANOVA (genotype status $X$ time period) with repeated measures on time period.

Social interaction test. The general design was adapted from a published protocol (Sams-Dodd, 1997). The test was performed in an open arena $(40 \times 40 \mathrm{~cm} ; 30 \mathrm{~cm}$ high) that was placed in a dimly lit room and cleaned after each test. Two unfamiliar mice of identical genotype that had approximately the same weight were placed simultaneously in the opposite corners of the arena. The track of each mouse was recorded for a $10 \mathrm{~min}$ period. Social interactions were measured by the time spent at a distance inferior to $8 \mathrm{~cm}$ and by the number of contacts made. During the $10 \mathrm{~min}$ period of the test the locomotor activity and time spent in the central zone also were recorded. The behavior of animals was followed with a video tracking system (SMART, Bioseb). Social interaction data were analyzed with the Student's $t$ test. When significant differences were found in social interaction and motor activity, ANCOVAs were conducted to determine phenotype independences.

Saccharin preference. The mice placed in individual cages 2 weeks before the test then were submitted to a water versus saccharin two-bottle preference test (saccharin sodium salt hydrate; Sigma). Increasing saccharin solutions were used $(0.0125,0.05,0.2,0.8$, and $3.2 \%)$. Each concentration was presented in consecutive $2 \mathrm{~d}$ blocks. The solutions were available $23 \mathrm{~h} / \mathrm{d}$, and the bottles were weighed and refilled during the remaining $1 \mathrm{~h}$. The left-right positions of the saccharin and water were alternated for each concentration (to control for the preference of some mice for a particular side). Total intakes were averaged and expressed in milliliters per day. A "Preference Index" was calculated by subtracting the "expected consumption" if there was no preference (total ingested fluid/2) from the actual amount of saccharin-containing liquid consumed (Meliska et al., 1995). Significance was calculated by two-way ANOVAs (genotype status $\times$ saccharin concentrations), followed by separate oneway ANOVAs and post hoc analysis (Fisher LSD) when appropriate.
A
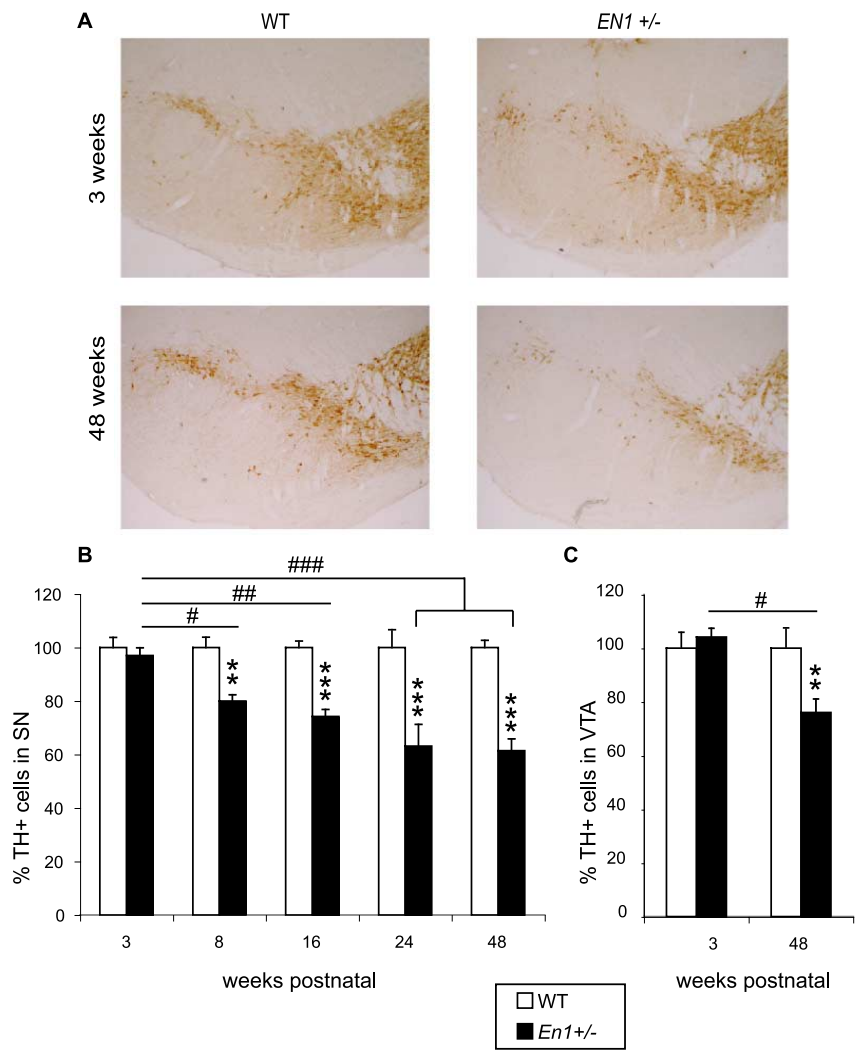

Figure 1. Progressive DA cell loss in the ventral midbrain of $E n 1+/-$ mice. $A$, TH-positive cells in the ventral midbrain of WT and $E n 1+/-$ mice at 3 and 48 weeks postnatal. $\boldsymbol{B}$, Progressive loss of DA neurons in $S N$ with age in $E n 1+/-$ mice $(3,8,16,24$, 48 weeks postnatal). En $1+/-$ versus WT, ${ }^{* *} p<0.01$ and ${ }^{* * *} p<0.001$ ( 3 vs 8 weeks, ${ }^{*} p<0.05$; vs 16 weeks, $\# p<0.01$; vs 24 and 48 weeks, ${ }^{\# \#} p<0.001$ ). Actual numbers from which percentages of surviving neurons were calculated at each age are provided in supplemental Table 1 (available at www.jneurosci.org as supplemental material). C, Loss of DA neurons in VTA of En1+/mice ( 3 and 48 weeks postnatal). For 48 versus 3 weeks, ${ }^{\#} p<0.05$; En $1+/-$ versus WT, ${ }^{* *} p<$ 0.01 ( $n=3-4$ by group of age and genotype).

\section{Results}

\section{Dopaminergic phenotype of En1+/- mice}

Illustrations of TH staining for DA cells and NeuN staining for total neuronal cells are provided in Figures $1 A$ and $2 C$ for WT and heterozygote mice $(E n 1+/-)$. We evaluated the number of TH-positive cells in the SN and VTA of En1+/- animals and their WT littermates at different time points (for SN, 3, 8, 16, 24, and 48 weeks postnatal; for VTA, 3 and 48 weeks postnatal). In the SN and VTA the overall ANOVAs revealed a significant genotype $\times$ age effect [for SN, $F_{(4,23)}=10(p<0.001)$; for VTA, $\left.F_{(1,8)}=11(p<0.05)\right]$ and were followed by post hoc Tukey HSD tests. At 3 weeks of age there is no difference in numbers of TH-expressing neurons between WT and En1+/- mice both in the SN and in the VTA (Fig. $1 B$ ). However, the percentage of $\mathrm{TH}$-positive cells decreases progressively in the mutant, and a difference of $19 \%$ between WT and $E n 1+/-$ is already present at 8 weeks $(p<0.01)$ in the SN. At 24 weeks the number of THpositive cells is reduced significantly by $38 \%$ in the mutant $(p<$ 0.001 ), and we could measure no additional loss between 24 and 48 weeks (Fig. $1 B$ ). The loss in TH-positive neurons at 48 weeks in the SN was twice that measured in the VTA $(23 \% ; p<0.01)$ (Fig. 1C).

Then the total number of neurons in the $\mathrm{SN}$ was quantified by using the pan-neuronal marker $\mathrm{NeuN}$ at 3 and 48 weeks postnatal. The overall ANOVAs revealed a significant phenotype $\times$ age 
effect $\left[F_{(1,8)}=16(p<0.01)\right]$. The post hoc Tukey HSD test demonstrated that, at 48 weeks, the mutant $\mathrm{SN}$ had lost $38 \%$ of its neurons, compared with WT $(p<0.001)$ (Fig. 2D). Thus the numbers of THpositive cells and NeuN-positive cells in the SN decreased in parallel, demonstrating that the decrease in TH-positive cells reflected cell death and not impaired $\mathrm{TH}$ expression. Compared with WT, the size of the SN was not modified with age in En1+/- (Fig. 2A,B).

Evaluation of DA contents in the striatum by liquid chromatography and mass spectrometry revealed a significant decrease of $37 \%$ in DA levels in the striatum of En1+/- mice $(p<0.01)$ (Fig. $2 E$ ). This measure of striatal DA content takes into account DA originating from the SN and the VTA terminals. Interestingly, the ratio of dihydroxyphenylacetic acid (DOPAC) on DA, an index of DA turnover, was increased by $23 \%$ in $E n 1+/-$ mice $(p<0.001)$ (Fig. $2 F)$. En $1+/-$ animals thus may compensate for DA cell loss by increasing DA turnover. It is noteworthy that the levels of striatal 5-HT were not modified in the mutant (Fig. $2 G$ ), suggesting that in the striatum the mutation primarily affected the DA pathway.

\section{En2 infusions antagonize the decrease in TH-positive cell numbers between weeks 6 and 9}

In several previous studies we have demonstrated that Engrailed is a messenger homeoprotein and is internalized (and secreted) by live cells thanks to the presence of two highly specific sequences (Prochiantz and Joliot, 2003; Joliot and Prochiantz, 2004).We used this property to develop a gain of function approach aimed at verifying that En2 and En1 are biochemically equivalent in the midbrain (Hanks et al., 1995) and that En1/2 are survival factors for DA neurons in vivo and in the adult. Based on the high interspecies conservation of En2, we use purified chick En2 for which biological activity after internalization previously had been demonstrated (Brunet et al., 2005). A difficulty was the technical impossibility to infuse the protein for $>2$ weeks. As illustrated in Figure $3 B$, the protein was infused at a concentration of $150 \mu \mathrm{g} / \mathrm{ml}$ between weeks 6 and 8 , and the animals were killed at week 9. This timing was dictated by the fact that the rate of cell death is slightly higher between weeks 5 and 8 and that 6 -week-old animals can be handled more easily than younger pups. Infusions were unilateral; En2 protein could diffuse through the entire midbrain (Fig. $3 A$ ), but the intensity and radius of diffusion of the protein were variable among animals. We then evaluated the number of THpositive cells in the SN ipsilateral to the infusion site. Two-way ANOVA revealed a significant treatment $\times$ genotype effect $\left[F_{(1,11)}=14.2(p<0.01)\right]$. The Fisher LSD post hoc test showed that the infusion had no effect on WT $[p=0.4$; not significant
B

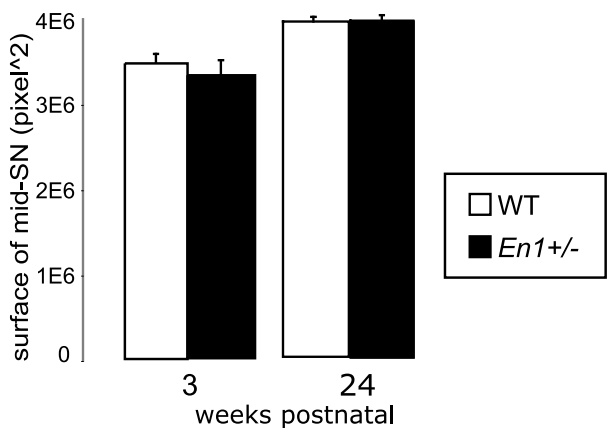

D

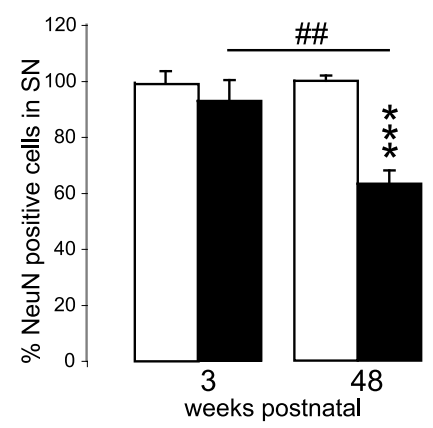

$\mathbf{F}$
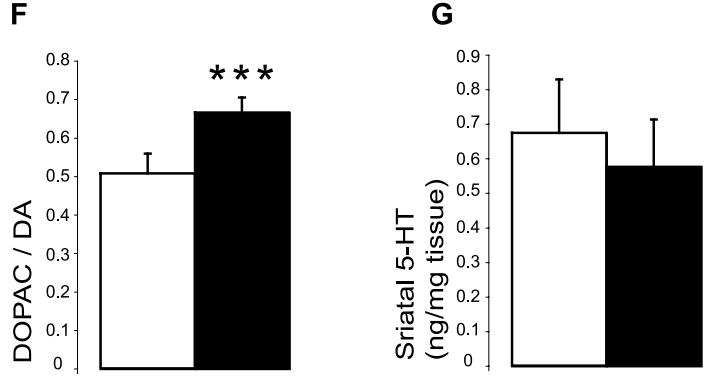

Figure 2. Neuronal cells in SN. $\boldsymbol{A}$, Middle section of the SN (mid-SN) stained for TH. The surface of the SN is outlined by the at 3 and 24 weeks of age. $C$, TH (red) and NeuN (green) staining of SN cells. Shown are examples of non-DA neurons (arrows) and of DA neurons (arrowheads; yellow; merged picture). D, Decrease of total neuron number in En1+/- versus WT mice between 3 numbers from which percentages of surviving neurons were calculated are provided in supplemental Table 1 (available at ww.jneurosci.org as supplemental material). $\boldsymbol{E}$, Striatal DA contents in WT $(n=8)$ and En1+/- $(n=10)$ mice at 55 weeks postnatal ( $\left.{ }^{* *} p<0.01\right)$. $\boldsymbol{F}$, DA turnover of WT and $E n 1+/-$ mice at 55 weeks postnatal $\left({ }^{* * *} p<0.001\right)$. G, Striatal serotonin (5-HT) contents in WT and En1+/- mice at 55 weeks postnatal (NS).

(NS) ], confirmed that at 9 weeks postnatal En1+/- animals (infused with saline) have significantly less $\mathrm{TH}$-positive cells than WT animals (infused with saline; $p<0.001$ ) (Fig. $3 C$ ), and finally demonstrated that En 2 protein can antagonize DA cell loss fully in the $\mathrm{SN}$ of En1+/- animals $(p<0.01)$ (Fig. $3 C)$. These data suggest that the DA cell death phenotype truly reflects a survival function of En1/2.

\section{Motor activities}

Spontaneous locomotor activity in a novel environment (open field) was investigated in WT and $E n 1+/-$ mice at 24 weeks of age (Fig. 4A-C). Compared with WT, En1+/- mice exhibited a reduction in distance traveled (Fig. $4 A)\left[F_{(1,36)}=7.66(p<\right.$ $0.01)]$. In both groups the locomotor activity decreased over time during the 15 min of observation $\left[F_{(2,72)}=143(p<0.001)\right]$ with no difference between the groups (period $\times$ genotype interac- 
A
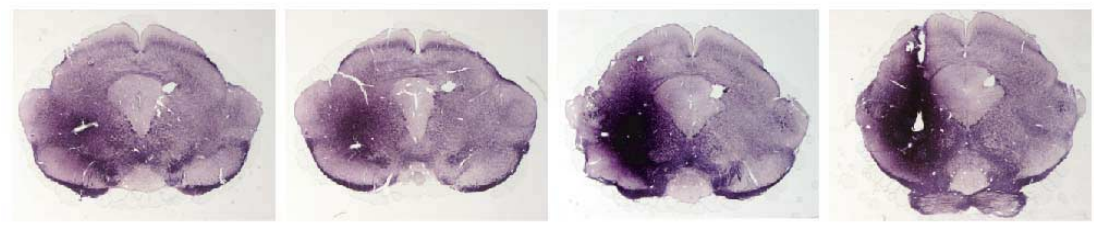

B

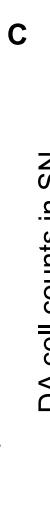

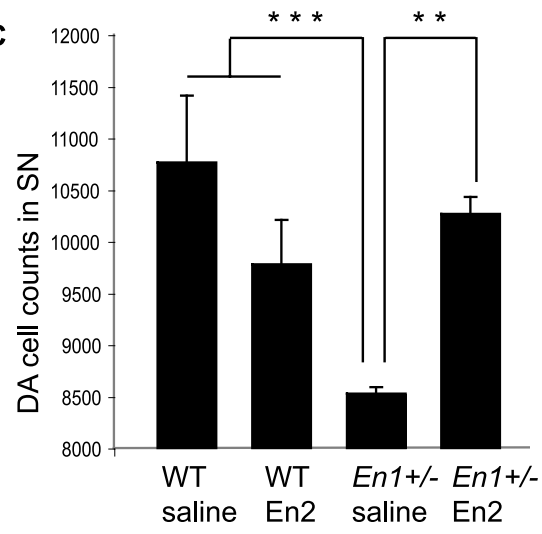

Figure 3. Gain of function by intraparenchymal infusion of En2 protein. $\boldsymbol{A}$, After $14 \mathrm{~d}$ of infusion, En2 is detected in a large amount in a region encompassing the SN. Anterior sections are to the left and posterior to the right. $\boldsymbol{B}$, Progressive loss of DA neurons in SN of En1+/ - mice compared with WT expressed as the mean \pm SD. At 3 weeks postnatal, the WT and En 1+/mice possess the same number of TH-positive cells in the SN. A decrease of $\sim 20 \%$ is observed at 8 weeks postnatal and of $\sim 28 \%$ at 16 weeks. Between 6 and 9 weeks postnatal, the $E n 1+/-$ mice lose $\sim 10 \%$ of DA cells. C, Rescue of DA cell loss in En1+/mice by En 2 infusion above the SN. At 9 weeks postnatal, the control En $1+/-$ mice have lost $\sim 20 \%$ of DA cells as compared with the WT (***p $<0.001)$. No significant difference in TH-positive cell numbers is found between WT infused with saline or WT infused with $\mathrm{En} 2$ ( $p=0.4$; NS). Infusion of $\mathrm{En} 2$ in $E n 1+/$ - mice prevents cell loss in the SN. At 9 weeks postnatal, after 2 weeks of En2 infusion, the number of TH-positive neurons is increased significantly by $\sim 15 \%$ in $E n 1+/-$ mice as compared with control $\left({ }^{* *} \mathrm{p}<0.01\right)$ and is equivalent to the number of DA cells in WT infused with saline or En2.

tion; $\left.F_{(2,72)}=1.2 ; \mathrm{NS}\right)$, indicating similar profiles of habituation. During the locomotor activity test En1 $1-/-$ mice also exhibited a reduced number of rearings as compared with WT mice (Fig. 4B) $\left[F_{(1,36)}=12.3(p<0.01)\right]$ whatever the period tested (period $\times$ genotype interaction; $F_{(2,72)}=1.3$; NS). Figure $4 C$ illustrates that En1+/- and WT mice spent similar amounts of time in the central area of the open field $\left(F_{(1,36)}=0.3\right.$; NS). This could be interpreted as an absence of difference in a behavior associated with anxiety. This interpretation was confirmed by the elevated plus maze also used as an anxiety test (supplemental Fig. 1, available at www.jneurosci.org as supplemental material).

Amphetamine-induced activity $(2 \mathrm{mg} / \mathrm{kg}$ ) was investigated in WT and $E n 1+/-$ mice at 32-33 weeks of age. During the $30 \mathrm{~min}$ preceding the injection of amphetamine or saline $E n 1+/-$ mice exhibited a lower motor activity than their WT littermates (data not shown). Post hoc analysis showed that in the three sessions, compared with WT, activity was decreased in En1+/- animals $(p<0.05)$. Amphetamine did not modify WT mice motor activity during the three sessions ( $p \leq 0.9$; NS) but induced an increase in activity in $E n 1+/-$ animals (Fig. $4 D$ ). This increase was not significant in session S1 but was significant in sessions S2 $(p<0.05)$ and S3 $(p<0.01)$ (Fig. 4D). These results show that, at this concentration, amphetamine induces a behavioral sensitization in En1+/- mice, but not in WT mice. Hyperactivity in WT and $E n 1+/-$ mice was induced with a higher dose of $5 \mathrm{mg} / \mathrm{kg}$ (data not shown). En1+/- mice were analyzed additionally in a rotarod test, which evaluates motor coordination and sensorimotor learning (Crawley, 1999) (Fig. 4E). En1+/- mice tended to fall earlier than WT mice $\left[F_{(1,17)}=2.7\right.$ $(p=0.11)]$ whatever the speed tested (genotype $\times$ speed; $F_{(4,68)}=0.4$; NS). However, this trend was not significant. The performance of both groups varied with speed $\left[F_{(4,68)}=2.9(p<0.05)\right]$, with stable performances from 16 to $24 \mathrm{rpm}$, followed by a decrease in stability when the speed was increased to 28 and $32 \mathrm{rpm}$ (at both speeds, $p<0.05$ in comparison to 16 $\mathrm{rpm})$. Although the differences between WT and En1+/- are not statistically significant, it must be noted that this is attributable to the exceptionally good performance of one of the mutants (of 10 animals in the group) and that removing this animal would lead to a significant difference of $p<0.01$ between the two groups.

\section{Nonmotor behavior \\ Forced swimming test}

Figure 5, $A$ and $B$, illustrates the performances of 24-week-old mice in the FST, a widely used paradigm to assess antidepressant activity (Porsolt et al., 1977; Cryan and Mombereau, 2004). With the use of the protocol of Cryan and Mombereau (2004), during the first exposure to the test situation (Fig. 5A) both WT and En1+/- mice show a typical pattern: an initial behavioral activation that is substituted progressively by increasing episodes of rigid immobility as revealed by a significant time period effect $\left[F_{(1,17)}=11(p<\right.$ $0.001)]$. In addition, the analysis also revealed a significant genotype effect $\left[F_{(1,17)}=8.5(p<0.01)\right]$ and a significant genotype $\times$ time period interaction $\left[F_{(1,17)}=108\right.$ $(p<0.01)]$. A post hoc test revealed that $E n 1+/-$ mice exhibit significantly more immobility than WT animals during the first 5 min of the test $(p<0.01)$, whereas during the last $5 \mathrm{~min}$ the immobility time is similar between WT and $E n 1+/-$ mice. During the second exposure (Fig. $5 B$ ) En1+/- mice exhibit a greater immobility time than WT mice $\left[F_{(1,17)}=6.9(p<\right.$ $0.05)]$ whatever the period tested, as revealed by the absence of time period $\times$ genotype interaction $\left(F_{(1,17)}=0.9 ; \mathrm{NS}\right)$. In addition, levels of immobility remained constant across periods $\left(F_{(1,17)}=0.4\right.$; NS).

Animals tested in FST have been evaluated previously in an open field to assess their locomotor activity (Fig. 5C). Compared with WT, En1+/- mice exhibit a reduction in distance traveled in an open field $\left[F_{(1,17)}=6.6(p<0.05)\right]$. In both groups locomotor activity decreases over time $\left[F_{(1,17)}=8.9(p<0.01)\right]$, with no difference between the groups $\left(F_{(1,17)}=1.2\right.$; NS). ANCOVA has been used to determine whether reduction of locomotor activity could be responsible for the increase in immobility time seen in the first $5 \mathrm{~min}$ in En1+/- mice. The ANCOVA revealed that immobility time (during the first day) is still increased significantly even when hypoactivity has been accounted for $\left[F_{(1,16)}=10.9(p<0.01)\right]$. Thus the FST test revealed a depressive-like behavior independent of the reduced locomotion observed in En1+/- mice. 
Saccharin consumption test

Saccharine intake was measured in 35week-old mice.

Preference Index for saccharine. The overall ANOVA revealed an impact of saccharin concentration on the Preference Index $\left[F_{(4,64)}=41.7(p<0.001)\right]$ (Fig. $6 A)$. There was also a significant concentration $\times$ genotype interaction effect $\left[F_{(4,64)}=4.5(p<0.01)\right]$, indicating that a difference of Preference Index between En1+/- and WT mice was not observed at all saccharin concentrations. Separate ANOVAs for each saccharin concentration or genotype revealed that (1) the Preference Index for saccharin is significantly higher in WT than in En1+/- mice at 0.2 and $0.8 \%$ and (2) the profile of saccharin intake differs between WT and En1+/mice. Indeed, for WT animals the analyses revealed a peak of saccharin intake at 0.2 and $0.8 \%$, whereas no preference for saccharine was observed in En1+/- mice at any concentration. Nevertheless, identical aversion was observed in WT and $E n 1+/-$ at the highest saccharin concentration $(3.2 \%)$. Together, these results suggest anhedonic-like behaviors in En1+/- mice.

Total fluid intake. As illustrated in Figure $6 B, E n 1+/-$ mice consumed significantly less fluid (saccharin plus water) than WT mice $\left[F_{(1,16)}=21.8(p<0.001)\right]$ whatever the saccharin concentration tested, as revealed by the absence of significant saccharin concentration $\times$ genotype effect $\left[F_{(4,64)}=2(p>0.05)\right]$, suggesting an adipsic behavior in $E n 1+/-$ mice. An increase in total volume intake at 0.2 and $0.8 \%$ saccharin $\left[F_{(4,64)}=8.2(p<0.001)\right]$ also was observed in WT mice.

\section{Social interaction}

Two unfamiliar mice (28-week-old mice) with identical genotypes that had approximately the same weight were placed simultaneously in the opposite corners of the arena to evaluate social behavior. Compared with WT, En1+/- mice spent significantly less time in social interaction $\left[236.9 \pm 35.6\right.$ vs $124.4 \pm 16.2 \mathrm{~s} ; t_{7}=3.1$ $(p<0.05)]$. En1 $+/-$ mice also showed a significant reduction in the number of contacts $\left[41.7 \pm 3.5\right.$ vs $23.6 \pm 1.7 ; t_{7}=$ $4.92(p<0.01)]$ and a significant decrease in locomotor activity during the $10 \mathrm{~min}$ period of social interaction $[3380 \pm 291 \mathrm{vs}$ $\left.2333 \pm 144 \mathrm{~cm} ; t_{16}=3.43(p<0.01)\right]$. No significant difference was observed in this time spent in the central zone between WT and En1+/- mice (117.9 \pm 11.6 vs $149.1 \pm 30.6 \mathrm{~s}$, respectively), confirming the absence of differences in anxiety-
A

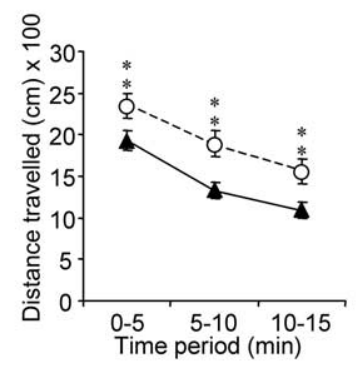

B

C

D
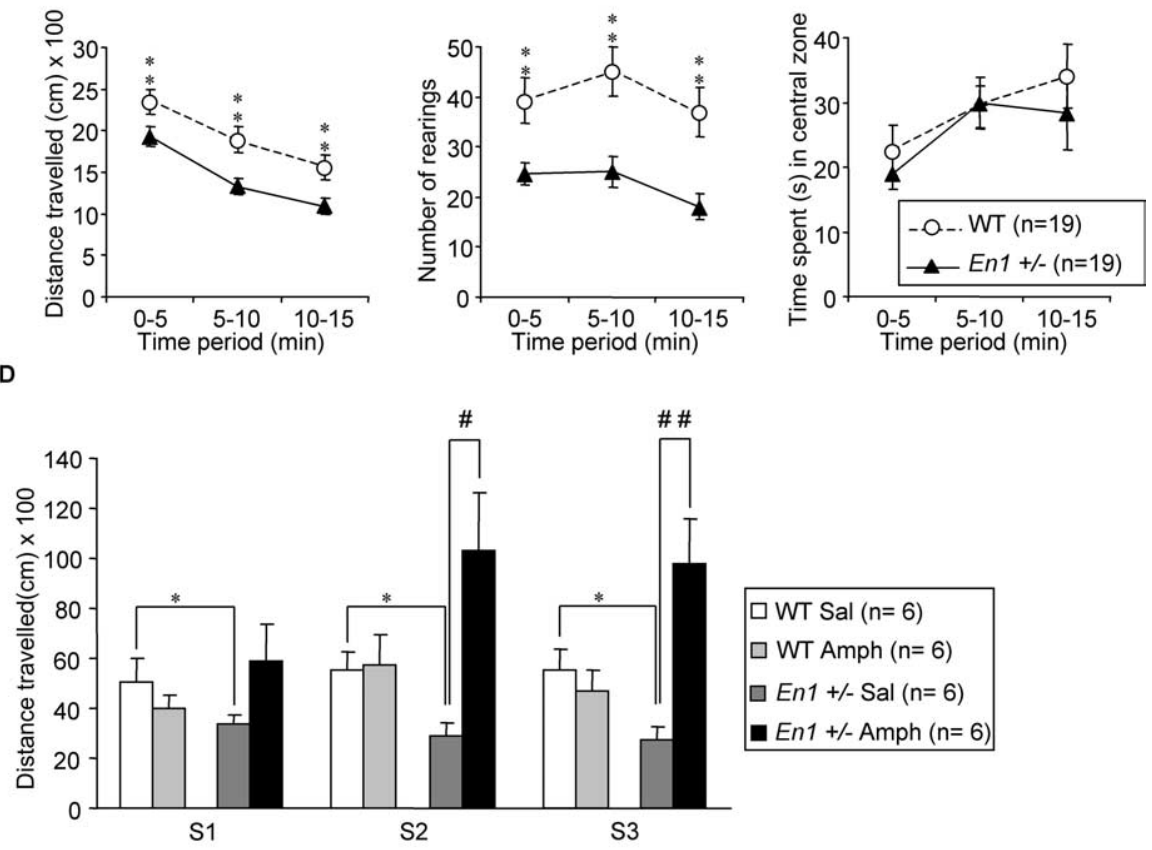

$\mathrm{E}$

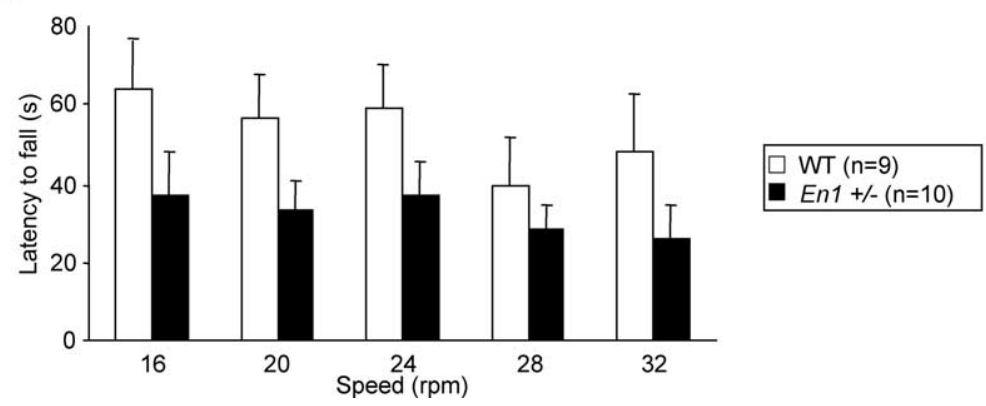

Figure 4. Locomotor activity. Performances in an open field of 24-week-old En1 $+/-$ and WT mice expressed as the mean \pm SD of distance traveled in centimeters $(\boldsymbol{A})$, number (mean \pm SD) of rearings $(\boldsymbol{B})$, and time spent in the central zone $(\boldsymbol{C})$; ${ }^{* *} p<$ 0.01. D, Effect of amphetamine $(2 \mathrm{mg} / \mathrm{kg})$ on the distance traveled in the open field (in centimeters; mean \pm SD) by WT and $E n 1+/-$ mice during the 30 min that follow injection. Mice are 32-33 weeks old at the time of the test. Animals receive either saline (Sal) or amphetamine (Amph). Differences (Student's $t$ test): En $1+/-$ versus WT, ${ }^{*} p<0.05$; Amph versus Sal, ${ }^{*} p<0.05$ and $^{\# \#} p<0.01$. Amphetamine administration at a dose of $5 \mathrm{mg} / \mathrm{kg}$ induces hyperactivity in both WT and $E n 1+1-$ mice (data not shown). $\boldsymbol{E}$, Rotarod performances of 27-week-old En1+/- and WT mice expressed as the mean \pm SD of latency (s) to fall (average of 3 trials). Although the same trend (decreased performance for $E n 1+/-$ mice) was observed at all speeds, the difference did not reach significance because of the abnormally high performances of one mutant mouse of 10 (see Results).
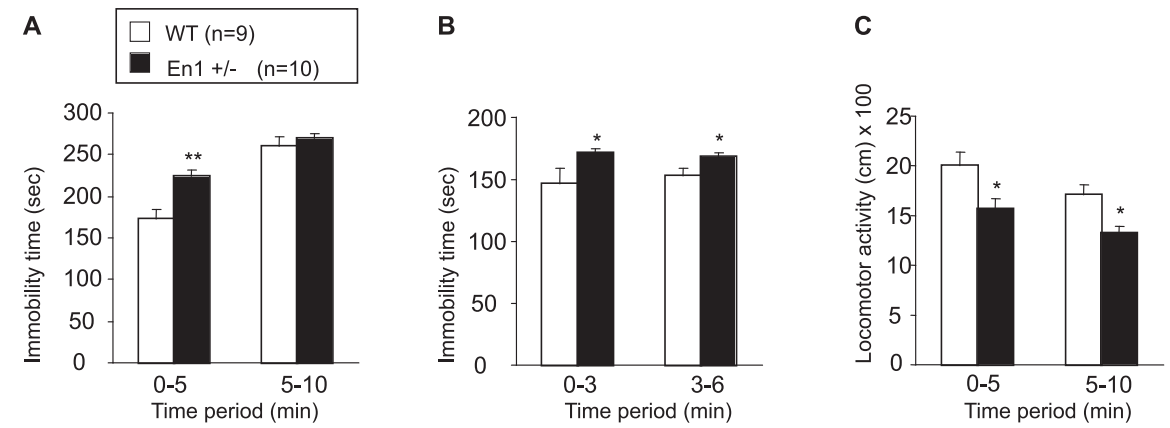

Figure 5. Forced swimming test. Performances of 26-week-old En1 $+/-$ and WT mice in forced swimming test are expressed as the mean \pm SD of immobility time during the first $(\boldsymbol{A})$ and the second $(\boldsymbol{B})$ test exposure; ${ }^{*} p<0.05$ and ${ }^{* *} p<0.01$. $\boldsymbol{C}$, Performances in an open field of 24-week-old En1+/- and WT mice tested in FST expressed as the mean \pm SD of the distance traveled (in centimeters); ${ }^{*} p<0.05$. 
A
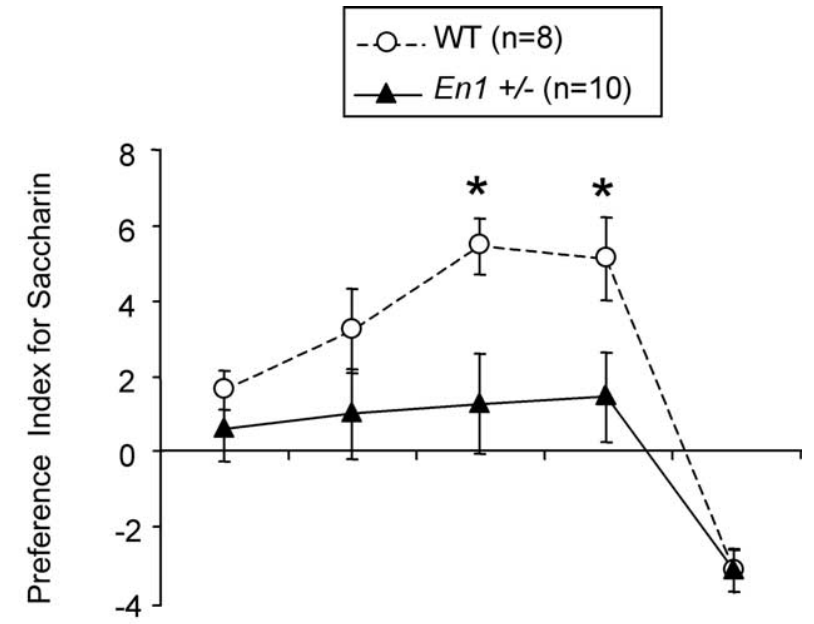

B

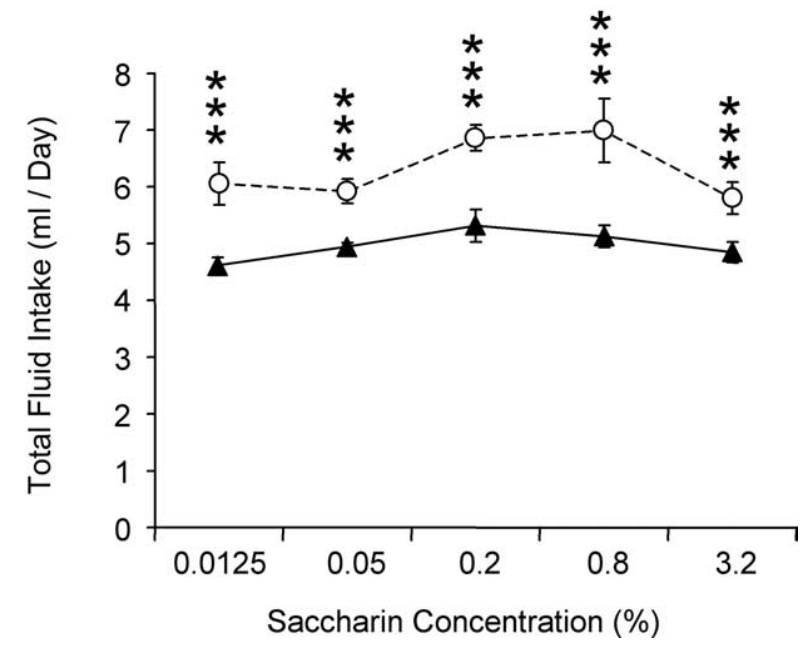

Figure 6. Saccharin consumption test. Shown is the Preference Index for saccharin $(A)$ and total fluid intake $(\boldsymbol{B})$ in 35-week-old $E n 1+/-$ and WT mice expressed as the mean \pm SD during a two-bottle free choice paradigm of saccharin consumption; ${ }^{*} p<0.05$ and ${ }^{* * *} p<$ 0.001 .

associated behaviors. ANCOVA was used to determine whether a reduction of locomotor activity could be responsible for the social interaction deficit found in En1+/- mice. The ANCOVA revealed that both decrease of time spent in contact and number of contacts were still significant when hypoactivity was accounted for $\left[F_{(1,15)}=12.6(p<0.01)\right.$ and $F_{(1,15)}=30(p<0.001)$, respectively].

\section{Discussion}

The aim of this study was to investigate the participation of Engrailed homeogenes in adult physiology. Engrailed (En1 and En2) control the development of several body structures. En1invalidated mice develop without midbrain and die before birth (Wurst et al., 1994). The phenotype of the En2 mutant is milder, with nonlethal cerebellar defects (Joyner et al., 1991). This is explained by the fact that $E n 1$, expressed before $E n 2$, compensates for the absence of the latter. The reverse compensation is demonstrated by the almost-normal brain phenotype of animals in which En2 was knocked into En1 (Hanks et al., 1995).

In the search for adult homeogene functions $E n 1 / 2$ are interesting because of their expression in structures of extreme physiological importance. Indeed, En2 is expressed strongly in the cerebellum, whereas En1 is abundant in the SN and VTA, two major DA nuclei of the ventral midbrain (Simon et al., 2001). The interest for these two structures is substantial because of their involvement in the regulation of motor behaviors and in the physiology of mood and reward (Graybiel et al., 1994).

Simon and colleagues (2001) showed that, approximately at birth, the number of surviving DA neurons in the midbrain is proportional to the number of En1/2 alleles expressed. More recently, Sgado and colleagues (2006) reported that, in a mouse mutant with one En1 allele in a En2-null context (three alleles missing), the number of DA neurons decreases rapidly in the $\mathrm{SN}$ of juvenile mice, with no death in the VTA. They mention that the En1 heterozygote in an En2 wild-type context maintains a normal number of DA neurons at all stages. This result differs from our finding that the latter genotype leads to DA cells death in the SN and the VTA. These discrepancies may be attributable to different genetic backgrounds (C57/BL6 vs Swiss).

Our study establishes that, at least until 3 weeks postnatal, En1+/- mice and WT animals from the same litter have the same number of TH-positive neurons both in the SN and VTA. At 8 weeks a decline in the number of TH-positive neurons can be seen in the $\mathrm{SN}$ of the heterozygotes, and the number of $\mathrm{TH}$ positive neurons declines progressively to reach a plateau after 6 months. Counting neurons in the SN with the help of NeuN, a pan-neural marker, demonstrates a parallel decrease in $\mathrm{TH}$ positive and NeuN-positive cells. We thus propose that the deletion of one Engrailed allele only induces the progressive death of DA neurons in the $\mathrm{SN}$ and, by extension, in the VTA.

The role of Engrailed proteins as survival factors was confirmed by infusion experiments based on the ability of extracellular Engrailed to gain access to the cell cytoplasm and nucleus (Prochiantz and Joliot, 2003; Joliot and Prochiantz, 2004). En2 infused above the SN diffuses into the ventral mesencephalon and blocks the death of SN neurons between weeks 6 and 9. This En2 gain of function experiment demonstrates that En2 and En1 are equivalent to promote DA cell survival without eliminating possible effects on TH expression.

It is surprising that a plateau is reached after 24 weeks with no additional cell death. This suggests that DA neurons in the SN and VTA are heterogeneous in terms of sensitivity to En dosage. Another possibility is that En $1 / 2$ also act as growth factors. Indeed, as with many other homeoproteins, they are secreted and internalized and therefore can act as signaling molecules, in particular via the regulation of local mRNA translation (Brunet et al., 2005). If so, in aged mutants the total amount of En $1 / 2$ produced in the ventral midbrain would be shared by a smaller number of DA neurons and would reach a "survival threshold." This possibility is illustrated by the rescue effect of infused En2, here used as a therapeutic protein.

En1+/- mice exhibit abnormal spontaneous motor activity in the open field. A deficit in motor coordination and sensorimotor learning was observed in the rotarod, although significance could be attained by removing one remarkably agile En1+/individual. This result fits with the decrease in striatal DA accompanying cell loss. Indeed, the nigrostriatal DA pathway is involved in initiating and coordinating locomotion. In addition, En1+/- mice show a strong sensitization to amphetamine after only one injection, suggesting an impaired activity of DA pathways implicated in behavioral sensitization (Kalivas and Stewart, 1991). A similar response to amphetamine was observed in adult mice that develop a hypo-DA phenotype after orthodenticle homolog 2 (Otx2) homeogene invalidation (Borgkvist et al., 2006). In our study strong hyperlocomotor activity was observed only at the second and third sessions, possibly because we used only 2 
$\mathrm{mg} / \mathrm{kg}$ (10 $\mathrm{mg} / \mathrm{kg}$ in the Otx2 study). In the two cases the decrease in striatal DA probably induces postsynaptic hypersensitivity (Borgkvist et al., 2006).

DA death in the VTA led us also to investigate nonmotor behavior deficits. The FST revealed a depressive-like behavior marked by an increase in immobility attributable to a reduced sensitivity of the mesolimbic dopamine system (Ventura et al., 2002). Anhedonia and adipsia observed in the saccharin consumption are unlikely to reflect, although we remain careful, a deficit in odorant and gustatory capacities, because mutant and WT mice were inhibited equally by the highest (3.2\%) saccharin concentration. Accordingly, an implication of the nigrostriatal pathway in adipsic behavior has been suggested (Casas et al., 2000; Pal et al., 2001). Finally, the mutants showed a strong decrease in social interactions, suggesting social anhedonia. Anhedonic-like behaviors observed in En1+/- animals can be attributed to the role played by the nucleus accumbens and its DA inputs from the VTA in drug and natural rewards (Kelley and Berridge, 2002; Wise, 2002).

Other genetic models showing the importance of developmental genes in DA survival and physiology have been described. In addition to En1/2 and Otx2, previously mentioned, $L m \times 1 b$, Nurr1, and Ptx3 (Eells, 2003; Nunes et al., 2003; Wallen and Perlmann, 2003; Smidt et al., 2004a) could be of particular interest. Nurr1 heterozygous and Pitx3 aphakia mice have a reduced number of nigrostriatal DA neurons. In Pitx3 mutants the DA loss is present at birth (van den Munckhof et al., 2003) and restricted to the SN (Smidt et al., 2004a). The Nurr1+/- mouse shows a reduced number of $\mathrm{TH}$-positive neurons at 60 weeks in the $\mathrm{SN}$, with an associated deficit in motor behavior (Jiang et al., 2005). A difference with the En1 model is that the number of DA cells is not modified, or only in toxic conditions (Eells et al., 2002; Jiang et al., 2005), and that the hypo-dopaminergic phenotype appears much later and seemingly reflects a downregulation of DA markers rather than cell loss.

This suggests that the En1+/- mutant might represent another model for diseases, neurological or psychiatric-associated with DA deficits. In particular, some traits could make it a useful tool in Parkinson's disease research (Fleming et al., 2005). Among these are the progressive loss of DA neurons and the differential loss between the VTA and the SN (Hirsch et al., 1988; Damier et al., 1999). Also, the association of motor deficits with anhedonia, decreased social interactions, and depression-like behaviors is reminiscent of traits observed in Parkinson's disease (Isella et al., 2003; Lemke et al., 2004; Lieberman, 2006). However, we do not pretend that this is the ultimate animal model for PD or any other DA-associated diseases, because the heterogeneity of most human neurological and psychiatric diseases makes it unlikely that any mouse model will fulfill the required criteria for such a claim. Our view is that most models that have been developed, genetic and pharmacological, are useful, each with its strengths and limitations.

In fact, our main message is that developmental genes expressed in the adult have important physiological functions. A lesson from the present study is that the deletion of one allele of four is enough to produce profound physiological modifications. This probably means that fluctuations, even minor, in En1/2 expression in the adult may have consequences on motor and mood behaviors, even in the absence of dramatic phenotypes. We thus speculate that the identification of the genetic pathways in which En1/2, but also other developmental genes with adult expression, are embedded will shed light on unforeseen aspects of adult phys- iology. It is our hope that this new knowledge will permit the identification of innovative therapeutic targets and strategies.

\section{References}

Alberi L, Sgado P, Simon HH (2004) Engrailed genes are cell-autonomously required to prevent apoptosis in mesencephalic dopaminergic neurons. Development 131:3229-3236.

Borgkvist A, Puelles E, Carta M, Acampora D, Ang SL, Wurst W, Goiny M, Fisone G, Simeone A, Usiello A (2006) Altered dopaminergic innervation and amphetamine response in adult Otx2 conditional mutant mice. Mol Cell Neurosci 31:293-302.

Brunet I, Weinl C, Piper M, Trembleau A, Volovitch M, Harris W, Prochiantz A, Holt C (2005) The transcription factor Engrailed-2 guides retinal axons. Nature 438:94-98.

Casas M, Prat G, Robledo P, Barbanoj M, Kulisevsky J, Jane F (2000) Methylxanthines reverse the adipsic and aphagic syndrome induced by bilateral 6-hydroxydopamine lesions of the nigrostriatal pathway in rats. Pharmacol Biochem Behav 66:257-263.

Crawley JN (1999) Behavioral phenotyping of transgenic and knockout mice: experimental design and evaluation of general health, sensory functions, motor abilities, and specific behavioral tests. Brain Res 835:18-26.

Cryan JF, Mombereau C (2004) In search of a depressed mouse: utility of models for studying depression-related behavior in genetically modified mice. Mol Psychiatry 9:326-357.

Damier P, Hirsch EC, Agid Y, Graybiel AM (1999) The substantia nigra of the human brain. I. Nigrosomes and the nigral matrix, a compartmental organization based on calbindin $\mathrm{D}_{28 \mathrm{~K}}$ immunohistochemistry. Brain 122[Pt 8]:1421-1436.

Eells JB (2003) The control of dopamine neuron development, function and survival: insights from transgenic mice and the relevance to human disease. Curr Med Chem 10:857-870.

Eells JB, Lipska BK, Yeung SK, Misler JA, Nikodem VM (2002) Nurr1-null heterozygous mice have reduced mesolimbic and mesocortical dopamine levels and increased stress-induced locomotor activity. Behav Brain Res 136:267-275.

Fleming SM, Fernagut PO, Chesselet MF (2005) Genetic mouse models of parkinsonism: strengths and limitations. NeuroRx 2:495-503.

Foucher I, Montesinos ML, Volovitch M, Prochiantz A, Trembleau A (2003) Joint regulation of the MAP1B promoter by HNF3 $\beta /$ Fox $\alpha 2$ and Engrailed is the result of a highly conserved mechanism for direct interaction of homeoproteins and Fox transcription factors. Development 130:1867-1876.

Gerlai R, Millen KJ, Herrup K, Fabien K, Joyner AL, Roder J (1996) Impaired motor learning performance in cerebellar En-2 mutant mice. Behav Neurosci 110:126-133.

Graybiel AM, Aosaki T, Flaherty AW, Kimura M (1994) The basal ganglia and adaptive motor control. Science 265:1826-1831.

Hanks M, Wurst W, Anson Cartwright L, Auerbach AB, Joyner AL (1995) Rescue of the En-1 mutant phenotype by replacement of En-1 with En-2. Science 269:679-682.

Hirsch E, Graybiel AM, Agid YA (1988) Melanized dopaminergic neurons are differentially susceptible to degeneration in Parkinson's disease. Nature 334:345-348.

Hoglinger GU, Feger J, Prigent A, Michel PP, Parain K, Champy P, Ruberg M, Oertel WH, Hirsch EC (2003) Chronic systemic complex I inhibition induces a hypokinetic multisystem degeneration in rats. J Neurochem 84:491-502.

Isella V, Iurlaro S, Piolti R, Ferrarese C, Frattola L, Appollonio I, Melzi P, Grimaldi M (2003) Physical anhedonia in Parkinson's disease. J Neurol Neurosurg Psychiatry 74:1308-1311.

Jiang C, Wan X, He Y, Pan T, Jankovic J, Le W (2005) Age-dependent dopaminergic dysfunction in Nurrl knockout mice. Exp Neurol 191:154-162.

Joliot A, Prochiantz A (2004) Transduction peptides: from technology to physiology. Nat Cell Biol 6:189-196.

Joyner AL, Herrup K, Auerbach BA, Davis CA, Rossant J (1991) Subtle cerebellar phenotype in mice homozygous for a targeted deletion of the En-2 homeobox. Science 251:1239-1243.

Kalivas PW, Stewart J (1991) Dopamine transmission in the initiation and expression of drug- and stress-induced sensitization of motor activity. Brain Res Brain Res Rev 16:223-244. 
Kelley AE, Berridge KC (2002) The neuroscience of natural rewards: relevance to addictive drugs. J Neurosci 22:3306-3311.

Lemke MR, Fuchs G, Gemende I, Herting B, Oehlwein C, Reichmann H, Rieke J, Volkmann J (2004) Depression and Parkinson's disease. J Neurol 251[Suppl 6]:VI/24-27.

Lieberman A (2006) Depression in Parkinson's disease-a review. Acta Neurol Scand 113:1-8.

Meliska CJ, Bartke A, McGlacken G, Jensen RA (1995) Ethanol, nicotine, amphetamine, and aspartame consumption and preferences in C57BL/6 and DBA/2 mice. Pharmacol Biochem Behav 50:619-626.

Morgan R (2006) Hox genes: a continuation of embryonic patterning? Trends Genet 22:67-69.

Nunes I, Tovmasian LT, Silva RM, Burke RE, Goff SP (2003) Pitx3 is required for development of substantia nigra dopaminergic neurons. Proc Natl Acad Sci USA 100:4245-4250.

Pal GK, Pal P, Raj SS, Mohan M (2001) Modulation of feeding and drinking behaviour by catecholamines injected into nucleus caudatus in rats. Indian J Physiol Pharmacol 45:172-180.

Pellow S, Chopin P, File SE, Briley M (1985) Validation of open/closed arm entries in an elevated plus-maze as a measure of anxiety in the rat. J Neurosci Methods 14:149-167.

Porsolt RD, Le Pichon M, Jalfre M (1977) Depression: a new animal model sensitive to antidepressant treatments. Nature 266:730-732.

Prakash N, Wurst W (2006) Development of dopaminergic neurons in the mammalian brain. Cell Mol Life Sci 63:187-206.

Prochiantz A, Joliot A (2003) Can transcription factors function as cell-cell signaling molecules? Nat Rev Mol Cell Biol 4:814-819.

Sams-Dodd F (1997) Effect of novel antipsychotic drugs on phencyclidineinduced stereotyped behaviour and social isolation in the rat social interaction test. Behav Pharmacol 8:196-215.
Sgado P, Alberi L, Gherbassi D, Galasso SL, Ramakers GM, Alavian KN, Smidt MP, Dyck RH, Simon HH (2006) Slow progressive degeneration of nigral dopaminergic neurons in postnatal Engrailed mutant mice. Proc Natl Acad Sci USA 103:15242-15247.

Simon HH, Saueressig H, Wurst W, Goulding MD, O'Leary DD (2001) Fate of midbrain dopaminergic neurons controlled by the Engrailed genes. J Neurosci 21:3126-3134.

Smidt MP, Smits SM, Bouwmeester H, Hamers FP, van der Linden AJ, Hellemons AJ, Graw J, Burbach JP (2004a) Early developmental failure of substantia nigra dopamine neurons in mice lacking the homeodomain gene Pitx3. Development 131:1145-1155.

Smidt MP, Smits SM, Burbach JP (2004b) Homeobox gene Pitx3 and its role in the development of dopamine neurons of the substantia nigra. Cell Tissue Res 318:35-43.

van den Munckhof P, Luk KC, Ste-Marie L, Montgomery J, Blanchet PJ, Sadikot AF, Drouin J (2003) Pitx3 is required for motor activity and for survival of a subset of midbrain dopaminergic neurons. Development 130:2535-2542.

Ventura R, Cabib S, Puglisi-Allegra S (2002) Genetic susceptibility of mesocortical dopamine to stress determines liability to inhibition of mesoaccumbens dopamine and to behavioral "despair" in a mouse model of depression. Neuroscience 115:999-1007.

Wallen A, Perlmann T (2003) Transcriptional control of dopamine neuron development. Ann NY Acad Sci 991:48-60.

Wise RA (2002) Brain reward circuitry: insights from unsensed incentives. Neuron 36:229-240.

Wurst W, Auerbach AB, Joyner AL (1994) Multiple developmental defects in Engrailed-1 mutant mice: an early mid-hindbrain deletion and patterning defects in forelimbs and sternum. Development 120:2065-2075. 